has been linked to ADHD. Mice lacking expression of this gene were more active than control littermates. Functional variants of genes involved in dopamine transmission may confer a familial risk for ADHD. (State MW, Lombroso PJ, Pauls DL, Leckman JF. The genetics of childhood psychiatric disorders: a decade of progress. LAm Acad Child Adolesc Psychiatry August 2000;39:946-958). (Respond: Dr Leckman, Child Study Center I-269 SHM, Yale University School of Medicine, 230 South Frontage Road, PO Box 207900, New Haven, CT 06520).

COMMENT. Abstracts of posters presented at the VIIIth World Congress on Psychiatric Genetics, Versailles, France, August 2000, are published in the Aug 7 issue of the American Iournal of Medical Genetics 96:452-571. Further evidence of linkage and association between ADHD and DRD4 polymorphism is presented but results were marginal.

Parental ADHD. Weiss M, Hechtman L, and Weiss G provide a clinical perspective on $A D H D$ in parents ( $\perp$ Am Acad Child Adolesc Psychiatry Aug 2000;39:1059-1061). ADHD is highly familial. More than 50\% of parents with ADHD have a child with $\mathrm{ADHD}$, and $25 \%$ of children with $\mathrm{ADHD}$ have an ADHD parent. Siblings are frequently affected, and families with multiple ADHD members are especially challenged. Parents with ADHD are recognized for their failure to keep appointments for the child patient, they are restless in the office, they forget to bring along school reports, and they monopolize the interview. Parental ADHD can impact family functioning and the treatment of the child. Family counseling must address both the child's and parent's problems.

Executive functions and ADHD are reviewed by Barkley RA in Part 1 of a series of columns on the Genetics of ADHD (I Am Acad Child Adolesc Psychiatry Aug 2000;39:1064-1068). The term executive function, deficient in ADHD, includes purposive, goal-directed activity; inhibition of distraction; response inhibition or delayed gratification; selective problem-solving; flexibility; goal persistence; and self-awareness. Self-regulation is essential for normal executive function. The prefrontal cortex is the anatomic localization of these functions. Attention deficits typical of ADHD are termed intention deficits.

\title{
COMMUNITY PERSPECTIVE ON STIMULANT THERAPY FOR ADHD
}

The use of stimulant medications in relation to diagnoses of attentiondeficit hyperactivity disorder (ADHD) was reviewed in interviews with 9- to 16year-olds from the Greai Smoky Mountains Study and reported from Duke University Medical Center, Durham, NC. Among children meeting DSM-III-R criteria by parental reports, $72 \%$ received stimulant medication. In those meeting full criteria for diagnosis, boys and younger children were more likely to receive treatment than girls and older children. In this rural community, $7.3 \%$ of children had received stimulants, more than twice the number diagnosed with $\mathrm{ADHD}$. The mean duration of treatment was 50 months. Comorbidity with ODD increased the rate of stimulant therapy. Among children not recognized by parents as ADHD, $29 \%$ received stimulant therapy. Stimulants were also prescribed for children without teacher confirmation of ADHD. Among adverse events, tics occurred in $3.9 \%$ of children receiving stimulants, compared with $0.4 \%$ of children who were never treated. (Angold A, Erkanli A, Egger HL, Costello EJ. Stimulant treatment for children: a community perspective. I Am Acad Child Adolesc Psychiatry August 2000;39:975-984). (Reprints: Dr Angold, Developmental Epidemiology Program, DUMC Box 3454, Durham, NC 27710). 
COMMENT. Practitioners in this rural community are marching to a different drummer than that proposed by the DSM criteria for the diagnosis and usage of stimulant medication for ADHD. Why some of these children were started, and maintained on stimulants for periods longer than is usual, and others left untreated, is unexplained. Questions posed by Dr Dulcan in her editorial note and as yet unanswered draw attention to possible overenthusiasm in usage of stimulants by one or two physicians, differences in the population in this area, and an apparent under estimate of ADHD diagnostic symptoms because stimulants were working. Perhaps there are criteria for stimulant usage not included in the DSM diagnoses.

Stimulant-associated adverse events. The confirmation of a correlation between tics and stimulants should introduce a reason for caution and avoidance of indiscriminate over-prescribing. Other under-emphasized but troublesome adverse effects of excessive dosage are possible cardiac problems.

An 8-year-old patient, recently presenting in our clinic for neurologic consultation, was reported to be taking 4 capsules of sustained-release methylphenidaie, a iotal of $80 \mathrm{mg}$ daily, for ADHD. A systolic heart murmur was detected, and an electrocardiogram revealed a prolonged QT interval. A few days following the discontinuance of stimulant treatment, a repeat ECG was reported

normal. In the office, there was no evidence of hyperactivity, distractibility, or impulsive behavior, either on or off medication. During summer vacation, a teacher report was unavailable to confirm or refute symptoms of ADHD reported by the parents.

\section{DEVELOPMENTAL AND DEGENERATIVE DISABILITIES}

\section{EXTREMELY PRETERM INFANTS AND NEUROLOGIC DISABILITY}

Of 308 surviving children, born at 25 or fewer weeks of gestation in the United Kingdom and Ireland, 283 (92\%) were examined at a median age of 30 months, and results reported from the School of Human Development, University of Nottingham, UK. Mean scores on the Bayley Mental and Psychomotor Developmental Indexes were 84 and 87 , respectively. Nineteen percent (53 children) had severely delayed development ( $>3$ SD below the mean), and 11\% (32) had scores from 2 SD to 3 SD below the mean. Ten percent had severe neuromotor disability, $2 \%$ were blind, and $3 \%$ were hearing impaired. Overall, almost $50 \%$ were disabled, boys more than girls. (Wood NS, Marlow N, Costeloe, et al, for the EPICure Study Group. Neurologic and developmental disability after extremely preterm birth. N Fngl I Med August 10, 2000;343:378-384). (Reprints: Dr Marlow, Academic Division of Child Health, Level E East Block, Queen's Medical Centre, Nottingham NG7 2UH, UK).

COMMENT. In a large cohort of extremely preterm infants evaluated at a mean age of 2 and $1 / 2$ years, one half of all survivors had a disability involving mental and psychomotor development, neuromotor function, or sensory and communication function. One quarter were severely disabled. Of those with abnormal motor function, $75 \%$ were diagnosed with cerebral palsy. 